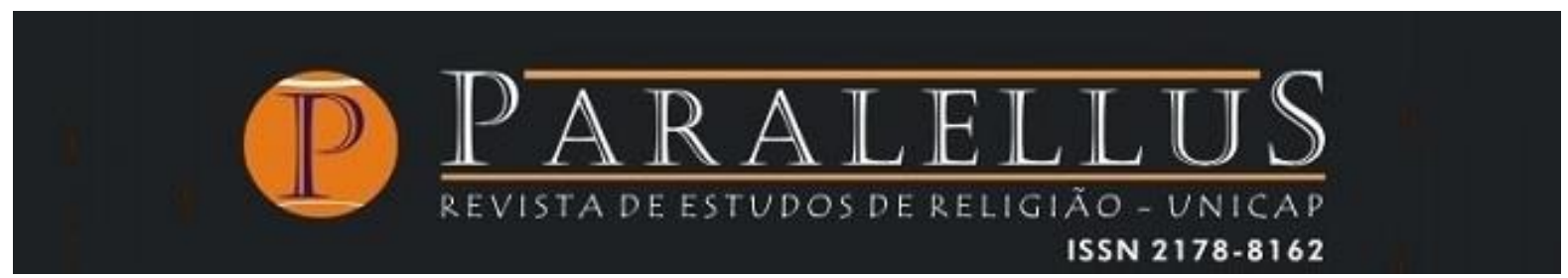

Volume 12 - Número 30

DOSSIÊ: A SABEDORIA NAS SAGRADAS ESCRITURAS

doi: 10.25247/paralellus.2021.v12n30.p347-351

\title{
SABEDORIA E RELIGIÃO
}

\section{WISDOM AND RELIGION}

João Luiz Correia Júnior*

A Sabedoria é uma fruta nutritiva e saborosa colhida na árvore do conhecimento prático das leis naturais que regem a vida. Desde a Antiguidade, o êxito na vida depende da sapiência para viver em meio à complexidade da existência, na malha das relações humanas, buscando condições para sobreviver em situações de crise e de caos. Ser uma pessoa sábia supõe: proficiência em algum tipo de atividade que atenda demandas da comunidade; inteligência emocional para lidar com o outro nas diversas relações socioafetivas; e capacidade para interagir com forças naturais circundantes, na busca incansável de manter sob controle as energias maléficas e liberar as benéficas.

Daí a importância da experiência acumulada dos ancestrais, da recapitulação dos costumes e das normas que contribuem para a convivência comunitária, por meio das instruções das pessoas sábias. Quem escuta com atenção e coloca em prática esses ensinamentos, trilha o caminho da profícua convivência no grupo a que pertence, contribuindo efetivamente para o bem comum.

A Religião surge, nesse contexto, como importante instrumento cultural que reforça a reflexão sobre valores sapienciais a serem seguidos, ressignificando situações existenciais na busca pelo sentido da vida. E o faz por meio de centros religiosos e templos sagrados que oportunizam espaço para o acompanhamento de mestres

\footnotetext{
* João Luiz Correia Júnior é professor pesquisador da UNICAP. Leciona no Bacharelado em Teologia e nos Programas de Pós-graduação em Teologia e em Ciências da Religião.
} 
espirituais, para o encontro comunitário em celebrações e ambientes apropriados para a meditação, oração e contemplação

A partir desse entrelaçamento entre tradição sapiencial e experiência religiosa, os valores sapienciais são ensinados e vivenciados como vontade de Deus. A própria compreensão sobre Deus, na cultura do Antigo Israel, chega mesmo a afirmá-lo como a Sabedoria por excelência, que pode ser constatada e contemplada na maravilhosa obra da criação.

Hoje, no contexto de crise de valores humanos da contemporaneidade, urge provocar a curiosidade acadêmica para a sabedoria prática como valiosa forma de conhecimento que abre caminhos, inclusive, para a busca de sentido da existência humana numa correlação sociocultural e socioambiental, numa perspectiva integradora, holística. Um tanto dessa vasta experiência integradora foi alicerçando culturas religiosas complexas, tais como as da África, desde tempos imemoriais, até às culturas das grandes civilizações no Egito, Mesopotâmia, Índia e Oriente.

A Revista Paralellus, no campo epistemológico das Ciências da Religião, que inclui várias áreas dos saberes acadêmicos, por meio desta edição, dá lugar a artigos que confirmam a importância da tradição sapiencial presente na cultura oral e em trechos da Literatura Sagrada, assunto estudado à luz da História, da Antropologia, da Exegese, da Hermenêutica e da Filosofia. Pelos estudos apresentados, fica evidente a pertinência da Sabedoria para a melhoria da qualidade de vida das pessoas, da convivência em suas comunidades e da compreensão e acesso a todas as culturas, ao longo dos séculos, inclusive na contemporaneidade.

Desse modo, já adentrando ao tema, chegamos ao primeiro artigo, cujo título é "Interpelación Bíblica y Relatos Americanos". Tem como objetivo considerar as sabedorias em diversos povos, com atenção especial a seus significados polissêmicos. Chega-se à conclusão de que o sapiencial é um grande componente da transmissão de vivências religiosas e de horizontes de esperança.

Em seguida, o texto intitulado "Aprendendo sobre Educação com a Filosofia Madhyamaka" enfrenta questões importantes que dizem respeito aos processos de ensino e de aprendizagem, tão importante para a transmissão do conhecimento e da 
sabedoria. Nele, a autora levanta reflexões sobre: que é aprender? Qual é o propósito da educação? Como ensinar? Em busca de respostas, inspira-se na tradição budista Madhyamaka (Índia), concluindo que os sistemas filosóficos e religiosos antigos possuem um vasto cabedal de conhecimento pouco "traduzido" para a linguagem acadêmica, e a educação moderna poderia se beneficiar desses conhecimentos milenares como estratégia que contribuiria para uma sociedade mais equilibrada.

O terceiro artigo tem como título "Da Milenar Sabedoria das Pessoas Idosas aos Livros Sapienciais". Busca-se explicar como se deu, ao longo da história, a transmissão da sabedoria por meio da cultura oral, até chegar ao texto escrito sapiencial. Pessoas mais velhas, letradas ou iletradas, desde o ciclo familiar nas pequenas aldeias até os sábios das escolas rabínicas, todos deram importante contributo para a cultura sapiencial do Judaísmo, preservada em seus textos sagrados.

Dentro da cultura religiosa judaica, um texto poético proveniente da sabedoria popular que valoriza a dimensão do amor, intitulado Cântico dos Cânticos, é incorporado à Sagrada Escritura. Trata-se de um texto que liberta o corpo de todo tipo de aprisionamentos. Este é o tema do artigo intitulado "Diante da política opressora, os corpos dos enamorados acenam rebeliões (Ct 6,4 - 7,10)". Trata-se de um artigo provocador que faz contraponto entre "corpos vitimados" em ações repressivas de agentes policiais, e "corpos de enamorados", a partir do quinto poema do livro Cântico dos Cânticos, interpretado como "um legítimo movimento de reviravolta frente ao modelo teocrático que se instalou em Judá, no período persa (Ct 6,4-7,10).

No artigo "Onde está a Sabedoria? (Jó 28,12): os Limites do Conhecimento Humano" a reflexão desenvolvida parte do princípio de que a sabedoria pode ser identificada como a busca do ser humano por autocompreensão. É um conhecimento proveniente da experiência existencial que se dá, essencialmente, na relação consigo mesmo, com os demais, em comunidade, tendo como finalidade enfrentar os desafios da sobrevivência e do bem-estar. Dessa preocupação com a vida prática, teriam surgido, em Israel, as tradições e escolas sapienciais, que 
definiram a sabedoria como um dom de Deus acessível a todas as pessoas de boa vontade.

Em "A Disponibilidade e Indisponibilidade da Sabedoria: a Dialética da Sabedoria em Provérbios e Jó", são apresentados trechos do livro dos Provérbios (1,20-33; 8,1-36; 9,1-6) e do livro de Jó $(28,1-28)$ com o objetivo de demonstrar estratégias literárias por meio das quais a Sabedoria é apresentada paradoxalmente como disponível (Provérbios) e indisponível (Jó) ao ser humano. No conjunto da Sabedoria bíblica, essa dialética aponta para a experiência humana que ora cultiva a sabedoria oriunda da vida cotidiana, ora não pode lidar com os mistérios da vida.

A partir do tema polêmico sobre a impossibilidade de uma pessoa rica entrar no Reino de Deus, o artigo intitulado "Sobre Camelos e Agulhas: notas sobre a História de um Dito Atribuído a Jesus" apresenta interessante pesquisa, a partir de relatos presentes no Novo Testamento, na literatura relacionada aos chamados "padres da Igreja" e numa passagem hoje encontrada no Corão muçulmano. O estudo joga luzes sobre uma temática sempre sensível quando se pensa a relação entre Religião e Sociedades: a da riqueza material, sua posse e usufruto.

Dando continuidade ao tema da Sabedoria no Segundo Testamento da Bíblia (Novo Testamento), o texto "Provérbios e Ditos na Boca do Sábio Popular Jesus de Nazaré" ressalta que, por meio do uso de parábolas e de ditados, Jesus demonstra familiaridade com a Sabedoria Popular e com o domínio da linguagem do seu contexto histórico, com a finalidade didática de provocar e sacudir seus ouvintes à mudança existencial e social. A partir dessa constatação, o autor analisa diversos aspectos da familiaridade de Jesus com o uso de ditados e provérbios, conforme relatado pelos Evangelhos, na esteira da tradição sapiencial; explica a fonte desses ditos, e a identificada como fonte $Q$, o evangelho radical da Galileia; distingue a identificação de Jesus como "a Sabedoria" (sofia ou logos), "filho da Sabedoria", da outra identificação de Jesus como sábio popular, contador de parábolas, ditos e provérbios.

Ao trazer o tema da Sabedoria para a contemporaneidade, o artigo "A Interpretação Bíblica de Francisco Julião no Eito da Cana" apresenta a ação de um socialista convicto, autodeclarado ateu, utilizando textos bíblicos para explicar e por em 
questão a situação de miséria em que viviam os camponeses que trabalhavam no eito da cana. Chega-se à conclusão de que Francisco Julião foi uma voz profética que denunciou a situação das pessoas que trabalhavam sob o jugo dos latifundiários. Sua interpretação da Bíblia inspira a que se produza uma hermenêutica crítica contextualizada.

O interessante artigo "A Sabedoria Prática na Literatura de Cordel", ressalta que, tomando-se o Cordel como exemplo, constata-se a presença de uma Sabedoria Prática em conexão com textos bíblicos. Infere-se, desse modo, que essa literatura genuinamente popular, pode trazer grandes contribuições para o estudo da religiosidade do povo.

Por fim, ao tratar da busca por sentido na contemporaneidade, algo tão próprio da literatura sapiencial, o texto intitulado "O Homo Religiosus segundo Viktor Frankl: apontamentos para uma Filosofia da Religião" surge com o objetivo de demonstrar que é possível extrair das obras do autor supracitado elementos para uma reflexão sobre o tema, a partir do ponto de vista da Filosofia da Religião.

Ao concluir este Editorial, fica declarado o desejo de que este número da Revista Paralellus suscite o interesse em aprofundar, ainda mais, os temas trabalhados neste Dossiê. Toda a Equipe Editorial aproveita para expressar profunda gratidão aos articulistas e pareceristas ad hoc.

Bom proveito! 